\title{
Application of Data Assimilation with the Root Zone Water Quality Model for Soil Moisture Profile Estimation in the Upper Cedar Creek, Indiana
}

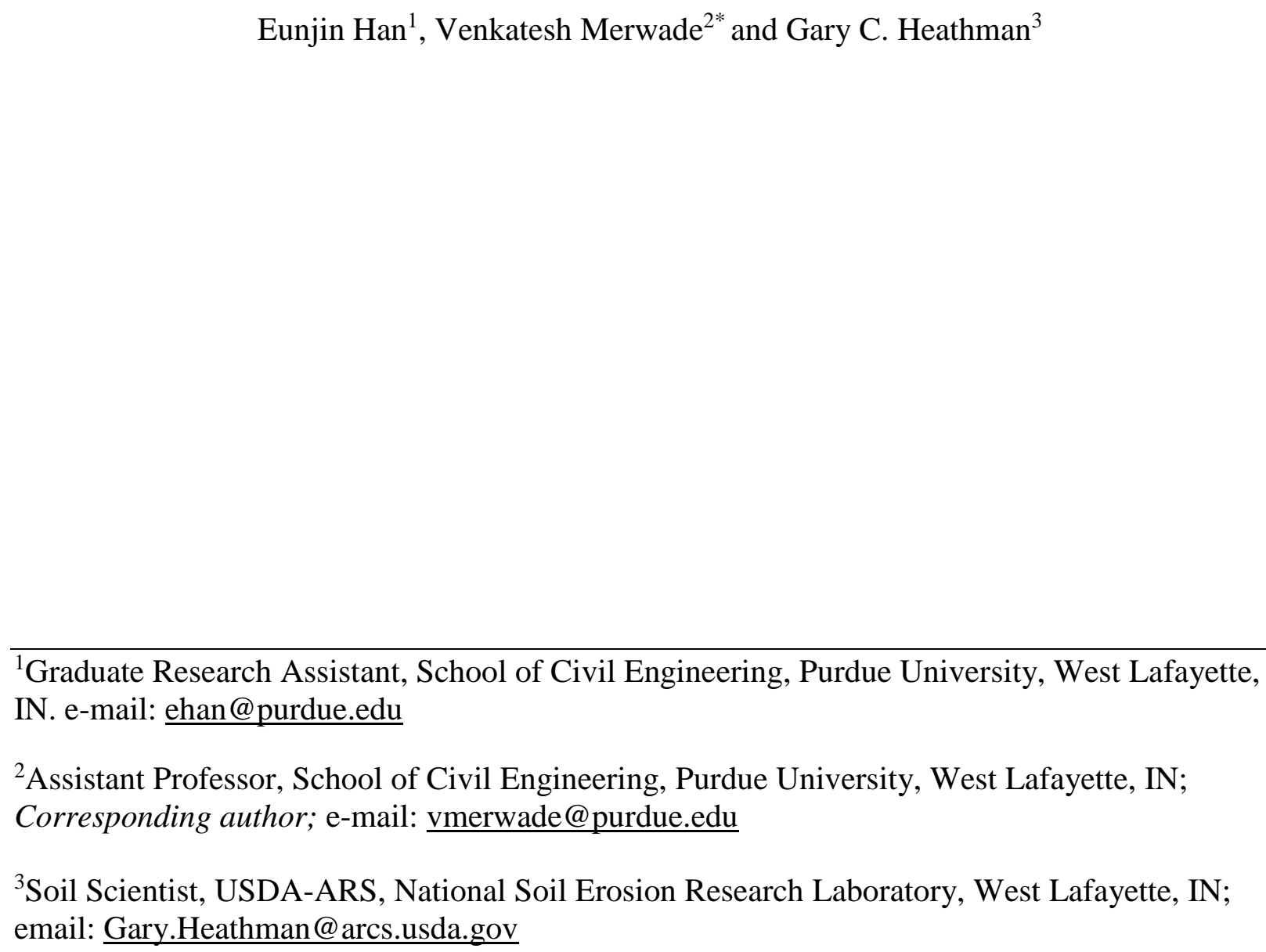
IN. e-mail: ehan@purdue.edu

${ }^{2}$ Assistant Professor, School of Civil Engineering, Purdue University, West Lafayette, IN; Corresponding author; e-mail: vmerwade@purdue.edu

${ }^{3}$ Soil Scientist, USDA-ARS, National Soil Erosion Research Laboratory, West Lafayette, IN; email: Gary.Heathman@arcs.usda.gov 


\section{Abstract}

Data assimilation techniques have been proven as an effective tool to improve model forecasts by combining information about observed variables in many areas. This paper examines the potential of assimilating surface soil moisture observations into a field-scale hydrologic model,

the Root Zone Water Quality Model, to improve soil moisture estimation. The Ensemble Kalman

Filter (EnKF), a popular data assimilation technique for non-linear systems, was applied and

compared to a simple direct insertion method. In situ soil moisture data at four different depths

$(5 \mathrm{~cm}, 20 \mathrm{~cm}, 40 \mathrm{~cm}$ and $60 \mathrm{~cm}$ ) from two agricultural fields (AS1 and AS2) in northeastern Indiana were used for assimilation and validation purposes. Through daily update, the EnKF improved soil moisture estimation compared to the direct insertion method and model results without assimilation, having more distinct improvement at the $5 \mathrm{~cm}$ and $20 \mathrm{~cm}$ depths than for deeper layers $(40 \mathrm{~cm}$ and $60 \mathrm{~cm}$ ). Local vertical soil property heterogeneity in AS1 deteriorated soil moisture estimates with the EnKF. Removal of systematic bias in the forecast model was found to be critical for more successful soil moisture data assimilation studies. The study also demonstrates that more frequent update generally contribute to enhance the open loop simulation, however, large forecasting error can prevent more frequent update from providing better results. In addition, results indicate that various ensemble sizes make little difference in the assimilation results. An ensemble of 100 members produced results that were comparable to results obtained from larger ensembles.

Key words: Soil Moisture; Root Zone Water Quality Model (RZWQM); Data Assimilation; Direct Insertion; Ensemble Kalman Filter; Cedar Creek Watershed 


\section{Introduction}

Estimation of soil moisture has received considerable attention in the areas of hydrology, agriculture, meteorology and environmental studies because of its role in the partitioning of water and energy at the land surface, specifically, precipitation into runoff and infiltration, and energy into latent and sensible heat fluxes. Better understanding and prediction of soil moisture in the root zone is beneficial in irrigation planning and crop management, flooding and drought prediction, water quality management, climate change and weather prediction. However, despite its significance, the expense associated with field measurements and high spatio-temporal variability of soil properties, have placed limitations in obtaining in situ measurements of profile soil moisture. Recent developments in remote sensing technology have provided possibilities to overcome these limitations through soil moisture retrieval from remote sensing images (Schmugge and Jackson, 1994; Jackson et al., 1995; Jackson and Vine, 1996; Jackson et al., 2002; Njoku et al., 2003; Verstraeten et al., 2006; Baup et al., 2007). However, in most cases, the actual sensing depth is limited to a few centimeters allowing soil moisture estimates for the top 0-5 $\mathrm{cm}$ and $1 \mathrm{~cm}$ surface layer using the L-band ( 1-2 GHz) and C-band ( 4-8 GHz), respectively (Jackson and Schmugge, 1989; Njoku et al., 2003).

Shallow soil moisture estimates from remotely sensed data has led researchers to integrate measured surface data and hydrologic models to obtain more accurate estimates of soil moisture content in the root zone through data assimilation techniques (Houser et al., 1998; Li and Islam, 1999; Hoeben and Troch, 2000; Walker et al., 2001b; Heathman et al., 2003a). Various data assimilation techniques have been used in soil moisture studies including the Kalman Filter(Hoeben and Troch, 2000; Walker et al., 2001b; Crosson et al., 2002), direct insertion method (Walker et al., 2001b; Heathman et al., 2003a), extended Kalman Filter (Reichle et al., 2002b; Seuffert et al., 2004; Draper et al., 2009) and Ensemble Kalman Filter (Reichle et al., 2002a, 2002b; Zhang et al., 2006). Among these techniques, the Ensemble Kalman Filter (EnKF) has been widely adopted because of its strength in handling non-linear systems and computational efficiency (Crow and Wood, 2003; Huang et al., 2008). As one of surface measurements from a remote platform, brightness temperature has been assimilated into hydrologic models for better estimation of soil moisture (Margulis et al., 2002; Crow and Wood, 2003; Huang et al., 2008). Recently, satellite-based surface soil moisture observation $(0-5 \mathrm{~cm})$ 
from the Scanning Channel Microwave Radiometer (SMMR) and the Advanced Microwave

2 Scanning Radiometer - Earth Observing System (AMSR-E) have been integrated with land

3 surface models through data assimilation (Reichle and Koster, 2005; Ni-Meister et al., 2006;

$4 \quad$ Reichle et al., 2007; Draper et al., 2009).

5 Most previous investigations that explored assimilation of remotely sensed surface soil moisture

6 involved regional or global scales for more accurate climate forecasts by improving temporal and

7 spatial soil moisture estimations (Walker and Houser, 2001; Reichle et al., 2002b; Ni-Meister,

8 2008; Draper et al., 2009). However, Troch et al. (2003) stressed the necessity of extending the

9 applicability of data assimilation, which has so far been studied in land surface models using

10 synthetic datasets, to many other important hydrological issues at catchment scale for a variety of

11 water resources management problems. Therefore, there is a strong need for more application-

12 focused research to determine the operational potentials of data assimilation within local scale

13 hydrologic modeling using actual observations.

14 There have been a few studies which have applied soil moisture data assimilation techniques for

15 improved hydrologic predictions at field or catchment scales. Walker et al. (2002) demonstrated feasibility of near-surface soil moisture assimilation to retrieve profile soil moisture in a 6 ha

17 catchment using a three dimensional distributed soil moisture model. In-situ soil moisture

18 observations in an agricultural field (21 ha) were used for soil moisture assimilation with the EnKF, specifically for correcting bias (De Lannoy et al., 2007a; De Lannoy et al., 2007b) and for applying an adaptive EnKF (De Lannoy et al., 2009), with the Community Land Model.

21 Recently, a catchment scale hydrologic model, Soil and Water Assessment Tool, was used to 22 investigate the performance of the EnKF for hydrologic predictions (Xie and Zhang, 2010; Chen 23 et al., 2011).

24 Heathman et al. (2003a) used a physically based and field-scale agricultural model, the Root 25 Zone Water Quality Model (RZWQM) to explore the possibility of assimilating observed surface soil moisture for better estimates of root zone soil water content. Based on substantial field

27 measured data, they showed that the direct insertion data assimilation technique produced 28 dynamics of model simulation results in the top $30 \mathrm{~cm}$ layers better than the model simulation without assimilation. Since they focused on using field measured surface soil moisture to 
estimate root zone soil water content rather than synthetic analyses, their study used the simple direct insertion method. As an extension to Heathman et al. (2003), this paper examines the benefit of assimilating surface soil moisture through the EnKF to improve model simulated soil moisture in the root zone using the RZWQM. In addition, contrary to many previous studies which assimilated remotely sensed surface soil moisture into land surface models at the regional or global scale, this study applies field measured surface soil moisture to a point scale model (RZWQM) for the purpose of data assimilation.

Field scale application of the EnKF in this study provides the fundamental groundwork necessary to advance our knowledge of surface soil moisture data assimilation in hydrologic modeling. First, field scale, deterministic models such as RZWQM can serve as the basis for the watershed scale hydrologic or water quality models (Abrahamson et al., 2006) and has been directed to extend the modeling methodology from one dimension to two or three dimensions (Walker et al., 2001a; Ma et al., 2007a). Second, in situ soil moisture observations have fewer uncertainties than the remotely sensed soil moisture data, which is better for testing different data assimilation schemes and validating the assimilation results more effectively. This is because observation errors for in situ soil moisture data can be estimated in a more reasonable way and thus, the in situ observations can be considered to represent the true system state with certain errors. Third, a field scale assimilation study can be based on more accurate soil characteristics data which are essential for water flow simulation in the unsaturated zone possibly reducing systematic model bias before assimilation. Walker et al., (2001a) discussed that incorrect information about soil porosity or residual soil moisture content restrained the soil moisture model from correct retrieval of profile soil moisture, even with an assimilation scheme. Lastly, it is possible with the field scale studies to investigate the impacts of local horizontal or vertical soil heterogeneity on data assimilation results, which is generally ignored in large scale studies.

RZWQM is one of the most representative agricultural system models with components for water movement, plant growth, and chemical transport with management effects (Ma et al., 2007a). Since its release in 1992 (Ahuja et al., 2000), RZWQM has been widely applied and tested in different areas for various purposes (Ma et al., 2001): to determine soil hydraulic properties (Cameira et al., 2000), to simulate tile drainage and leached nitrate (Abrahamson et al., 
2005; 2006), and crop production and nitrogen balances (Ma et al., 2007c). Among major components of RZWQM, soil hydrological components have performed satisfactorily (Cameira et al., 2000; 2005; Kozak et al., 2007) and soil water content were reasonably simulated (Farahani et al., 1999; Ma et al., 2003; 2007b; 2007c). In addition, RZWQM has been successfully used to induce saturated hydraulic conductivities for spatially distributed soils by coupling with microwave remotely sensed soil moisture (Mattikalli et al., 1998).

Thus, this study has the following three objectives: (i) apply EnKF to RZWQM using point scale soil moisture data; (ii) compare the results from EnKF application with simple direct insertion method; and (iii) explore the effect of ensemble size and update interval on model output. The above objectives were accomplished by using point scale profile soil moisture data collected for Upper Cedar Creek Watershed (UCCW) in northeast Indiana. Details of the study area including data acquisition are provided in the next section.

\section{Study area and data}

The Matson Ditch sub-catchment in the upper Cedar Creek Watershed located in northeastern Indiana (Fig. 1) was selected as the test bed for this study. Since 2004, the National Soil Erosion Research Laboratory (NSERL) of the USDA - Agricultural Research Service (ARS) has established an extensive soil moisture and weather monitoring network in the upper Cedar Creek Watershed as shown in Fig. 1. The weather stations in this network collect the following meteorological data for model simulations: ten minute rainfall, air temperature, solar radiation, wind speed, and relative humidity.

Among the ten soil monitoring sites within the upper Cedar Creek network, AS1 and AS2 fieldsize watersheds were selected for RZWQM simulations in this study because of the availability of measured soil properties data (e.g., soil texture, bulk density) and crop management information. The drainage area of the AS1 and AS2 field sites is 2.23 ha and 2.71 ha, respectively. Both sites are fairly flat (slope $<5 \%$ ), and are in agriculture production (alternative cropping of corn and soybean) with AS1 being in no-till, and AS2 under a rotational tillage system. The major soil types found at these sites are Glynwood (GnB2) silt loam (Fine, illitic, 
mesic Aquic Hapludalfs) for AS1 and Blount (BaB2) silt loam (Fine, illitic, mesic, Aeric

2 Epiaqualfs) for AS2.

3

The soil sensors in both fields are Stevens SDI-12 Hydra Probes that measure soil moisture and temperature every ten minutes by propagating an electromagnetic signal into the soil, which is a Frequency Domain Reflectometry (vs Time Domain Reflectometry). Out of four factory calibration equations for soil moisture measurements, the most current calibration equation (Equation 4) was used in this study. The calibration equation is based on the linear relationship between volumetric water content and the real component of the complex dielectric permittivity, which has been proven as reasonably accurate for many soils (Topp et al., 1980; Topp and Davis, 1985; Heathman et al., 2003b; Seyfried and Murdock, 2004). In addition, Seyfried et al. (2005) concluded that Equation 4 outperformed the other factory-supplied calibrations. According to texture analysis in our laboratory and Seyfried et al (2005), the calibration coefficients of the Equation 4 for loam soil type were determined. Since the Loam setting is applicable for Loam, Clay Loam, and Silty Clay Loam textures according to the Hydra Probe manual (Stevens Water Monitoring Systems, Inc., Portland, Oregon, USA, 2007), the selection of the calibration coefficients for loam is suitable for the soil types in this study (Table 1).

Soil moisture measurements were obtained at four depths by individual sensors installed at $5 \mathrm{~cm}$, $20 \mathrm{~cm}, 40 \mathrm{~cm}$ and $60 \mathrm{~cm}$. Accuracy of the soil moisture measurement is reported as \pm 0.03 water fraction by volume in typical soil by the manufacturer. Seyfried et al. (2005) demonstrated the dielectric loss corrected calibration could reduce soil moisture measurement errors. Considering that measured soil moisture in this study was not corrected with the dielectric loss and near saturated soil condition has the largest errors (Seyfried et al., 2005), actual observation error of the soil moisture may be slightly higher than $0.03 \mathrm{~m}^{3} \mathrm{~m}^{-3}$.

In this study, the measured surface soil moisture data $(5 \mathrm{~cm})$ are used for data assimilation, and the data at 5,20, 40 and $60 \mathrm{~cm}$ are used for validation purposes. In order to separate the observations that are assimilated into the model from the observations that are used to verify subsequent data assimilation results, especially for the $5 \mathrm{~cm}$ observations, the observations ( $Y_{k}$ in Equation (4)) are compared to the model predicted soil moisture before assimilation step ( $X_{k}^{i-}$ 
1 in Equation (6)) for results analysis. That is, the two sets of observations are considered

2 completely mutually exclusive. The measured soil moisture and temperature data are also used

3 to set up the initial conditions in RZWQM.

4 Measured soil moisture data during the simulation period (April - October 2007) at the two

5 study sites are displayed in Fig. 2. Observed meteorological data was collected at AS1, and used

6 as model input for both sites since the fields are less than $500 \mathrm{~m}$ apart. The top soil layers (0-5

$7 \mathrm{~cm}$ ), especially for AS1, show very dynamic variations in soil water content with rainfall;

8 whereas deeper layers show more stable soil water content conditions.

\section{3. Methodology}

10 In this experiment, we first ran the RZWQM with the input data described in the previous section 11 without any assimilation. This run is called the open loop simulation. Then the model was run 12 for the same period with two different data assimilation techniques: the direct insertion method 13 (DIR) and the Ensemble Kalman Filter (EnKF). The ability of the EnKF in improving the 14 simulated soil moisture profile is evaluated by comparing the results of the open loop and the 15 DIR. Time series graphs and statistical indices such as correlation coefficient, root mean square 16 error and mean bias error are used for the evaluation.

17 In this section, we begin with a brief description of the RZWQM focusing on hydrologic 18 processes, which is a model operator in the data assimilation system. A brief review of the EnKF 19 is given in section 3.2. Section 3.3 describes how the data assimilation algorithm is implemented 20 in the RZWQM to integrate observed surface soil moisture with the model prediction.

\subsection{Root Zone Water Quality Model (RZWQM)}

22 RZWQM is a physically based, one-dimensional deterministic model that uses fundamental flow 23 equations to simulate infiltration and redistribution in the subsurface region. During a rainfall 24 event, water infiltration is simulated by a modified form of the Green-Ampt equation (Equation 25 (1)) given below after (Ahuja et al., 2000). 
$1 \quad \mathrm{~V}=\mathrm{K}_{\mathrm{s}} \frac{\tau_{\mathrm{c}}+\mathrm{H}_{0}+\mathrm{Z}_{\mathrm{wf}}}{\mathrm{Z}_{\mathrm{wf}}}$

2 where $V$ is the infiltration rate at any given time $\left(\mathrm{cm} \mathrm{h}^{-1}\right), K_{s}$ is the effective average saturated

3 hydraulic conductivity of the wetting zone $\left(\mathrm{cm} \mathrm{h}^{-1}\right), \tau_{c}$ is the capillary drive or suction head at the

4 wetting front $(\mathrm{cm}), H_{0}$ is the depth of surface ponding $(\mathrm{cm})$, and $Z_{w f}$ is the depth of the wetting

5 front $(\mathrm{cm})$.

6 Redistribution between storm events is simulated by a mixed form of the Richards' equation as

7 given by Equation (2) after (Ahuja et al., 2000).

$8 \quad \frac{\partial \theta}{\partial \mathrm{t}}=\frac{\partial}{\partial \mathrm{z}}\left[K(h, z) \frac{\partial h}{\partial \mathrm{z}}-K(h, z)\right]-S(z, t)$

9 where $\theta$ is the volumetric soil water content $\left(\mathrm{cm}^{3} \mathrm{~cm}^{-3}\right), t$ is time (h), $z$ is the soil depth (cm), $h$ is 10 the soil-water pressure head $(\mathrm{cm}), K$ is the unsaturated hydraulic conductivity $\left(\mathrm{cm} \mathrm{h}^{-1}\right)$, and $S(\mathrm{z}, \mathrm{t})$ 11 is the sink term $\left(\mathrm{h}^{-1}\right)$.

12 RZWQM adopts a general mass-conservative numerical solution of Celia et al. (1990) to solve 13 the Richards' equation. The sink term takes into account plant water uptake and tile drainage, if 14 present. All other biological and chemical processes for plant growth and movement of nutrients 15 and pesticides in RZWQM are simulated following the physical water flow process. More 16 detailed information for biological and chemical processes in RZWQM can be found in Ahuja et 17 al. (2000).

18 Measured soil physical and hydraulic properties at the two sites (AS1 and AS2) were obtained from field samples analyzed at the NSERL lab or determined in situ and used as model input

20 (Table 1). RZWQM provides various options for the estimation of soil hydraulic properties 21 depending on the availability of the data (Ahuja et al., 2000). In this study, minimum necessary 22 input (soil texture, $-33 \mathrm{kPa}$ water content and bulk density for each soil layer) are provided and 23 other properties are estimated by the model (Table 1). For the constitutive relationship between $24 h-h-K$ which is a key for the numerical solution of the Richards' equation, RZWQM uses 25 functional forms of those relationships based on the modified Brooks-Corey equation. The 
1 parameters for the Brooks-Corey equation were compiled by Rawls et al. (1982) for major

2 USDA soil textures. Validation of this estimation technique can be found in Starks et al. (2003)

3 who showed that the limited input data option, based on textural class name, predicted soil water

4 content as well as the input from more detailed laboratory measurements. Thus, the parameter

5 values for Brooks-Corey equation are used from Rawls et al. (1982) in this study.

\section{$6 \quad 3.2$ Ensemble Kalman Filter (EnKF) Assimilation}

7 The main concept of EnKF, which includes forecasting the error statistics using Monte Carlo

8 methods, was first introduced by Evensen (1994), and has been applied to various fields,

9 especially in oceanography and meteorology (Evensen and Leeuwen, 1996; Burgers et al., 1998;

10 Keppenne, 2000; Houtekamer and Mitchell, 2001). There are slight differences between various

11 ensemble-based filter approaches. For instance, Houtekamer and Mitchell (1998) used two

12 ensembles of model states for forecasting, and updated each ensemble with error covariance

13 from the other ensemble. Whitaker and Hamill (2002) suggested a variant of the EnKF by

14 avoiding perturbation of observations. This study follows the algorithm proposed by Evensen

15 (2003,2004) and notation presented by Reichle et al. (2002b). In this approach, a non-linear

16 system model can be expressed with the following generic form:

$17 \quad \mathrm{X}_{k+1}=f_{k}\left(X_{k}\right)+w_{k}$

18 where $X_{k}$ is the system state of interest (in our case soil moisture water content), $f_{k}(\cdot)$ indicates

19 non-linear model operator at time step $k$, and $w_{k}$ is the system error that accounts for all

20 uncertainties in the model physics or forcing data. The $w_{k}$ term is treated as a normally

21 distributed random variable with zero mean and covariance $\mathrm{Q}_{k}$.

22 Observed soil moisture values $\left(\mathrm{Y}_{k}\right)$ are related to the true state $\left(X_{k}\right)$ through a measurement

23 operator $\left(H_{k}\right)$ as shown in Equation (4):

$24 \quad \mathrm{Y}_{\mathrm{k}}=H_{k} X_{k}+v_{k}$ 
1 Because measured soil moisture data are available in this study, $H_{k}$ is an identity matrix. The $v_{k}$

2 term represents errors in the measurement instrument and procedures, and conforms to a

3 Gaussian distribution with zero mean and covariance R.

4 The Kalman filter mainly consists of forecasting and updating steps (Gelb, 1974). Before starting

5 the forecasting or updating of EnKF, an initial ensemble of size $N$ is created by adding

6 pseudorandom noise $e_{i}$ with zero mean and covariance $P$ to get the first "guess" state $X_{0}$ as

7 shown in Equation (5) below.

$8 \quad X_{0}^{i+}=X_{0}+e_{i} \quad e_{i} \sim N(0, P) \quad i=1, \ldots ., N$.

9 As a next step, forecasting is performed to estimate the state at a future time by integrating the

10 initially created ensemble through the non-linear model operator, which in our study is

11 redistribution or the infiltration process.

$12 \quad X_{k}^{i-}=f_{k-1}\left(X_{k-1}^{i+}\right)+w_{k-1}^{i} \quad i=1, \ldots ., N$

13 In Equation (5) and (6), the superscripts '-' and '+' refer to state variables that are forecasted and

14 updated, respectively. In the standard Kalman filter algorithm, uncertainties in the system are

15 expressed with state error covariance. Contrary to the standard Kalman filter or extended Kalman

16 filter, the EnKF does not require the propagation of state error covariance $P_{k}^{-}$explicitly.

17 Propagation of state error covariance is computationally expensive for a large system, and its

18 exclusion is one of the advantages offered by the EnKF. Instead of forecasting the state error

19 covariance $P_{k}^{-}$from the covariance of the previous time step $P_{k-1}^{+}$, the EnKF estimates error

20 covariance from the forecasted ensemble of the state and their mean as shown in Equation (7)

21 below.

$22 \quad P_{k}^{-}=\frac{1}{N-1} D_{k} D_{k}^{T}$

23 where $D_{k}=\left[X_{k}^{1-}-X_{k}^{-}, \ldots . ., X_{k}^{N-}-X_{k}^{-}\right]$and $X_{k}^{-}=\frac{1}{N} \sum_{i=1}^{N} X_{k}^{i-}$ 
1 Whenever measured data are available, forecasted system variables are updated through the

2 weighted sum of forecasted variables and observed data. The Kalman gain, $K_{k}$ works as a weight

3 for the updating step as shown below.

$4 \quad K_{k}=P_{k}^{-} H_{k}^{T}\left[H_{k} P_{k}^{-} H_{k}^{T}+R_{k}\right]^{-1}$

$5 \quad X_{k}^{i+}=X_{k}^{i-}+K_{k}\left[Y_{k}-H_{k} X_{k}^{i-}+v_{k}^{i}\right] \quad i=1, . ., N$

6 As Equation (9) shows, in the update step, that the ensemble of observation size $N$ are created by

7 adding random perturbations $\left(v_{k}^{i}\right)$ with the mean equal to zero and observation variance $R_{k}$. After

8 each member of ensemble variables are updated, a best estimate of the system variable at time $k$

9 is found by averaging the updated ensemble members.

\subsection{Application of EnKF to RZWQM}

11 The basic framework of RZWQM, and how EnKF is incorporated into RZWQM processes is

12 presented in Fig. 3. Model initial conditions are set up using the observation data from the

13 previous day of the first simulation date. Initial ensemble members are generated by adding

14 random errors to the initial condition (Equation (5)). The initial covariance $P_{i}$ is determined by

15 averaging measurement variances at four measurement depths in the soil profile

$16\left(\left[V_{5 \mathrm{~cm}}+V_{20 \mathrm{~cm}}+V_{40 \mathrm{~cm}}+V_{60 \mathrm{~cm}}\right] / 4\right)$ from the actual ten minute data on the same day as the initial

17 condition. 100 ensemble members are used for all base simulations, but the effect of different

ensemble size is also investigated by changing the number of ensemble members from 50 to 500 .

Most of the subroutines in the RZWQM are based on a daily time step except the physical processes, which are based on a sub-hourly time step (Fig. 3). In addition, considering that

21 remotely sensed data from satellites are available on a daily time step or longer, the minimum

22 update interval for this study was taken as one day, even though application of more frequent

23 update interval is possible from the in situ ten minute observations. In order to find the optimum

24 frequency of surface soil moisture assimilation, different update intervals ranging from one day

25 to two weeks were examined in this study with 100 ensemble size. 
1 To evaluate the performance of EnKF compared to other data assimilation techniques, a simple

2 data assimilation scheme, direct insertion method, was also applied in this study. The direct

3 insertion method involves simply the substitution of available observed data for forecasted

4 system state variable. In this study, it was assumed that the top three numerical layers included in

5 the top $5 \mathrm{~cm}$ have the same observed soil moisture as the one measured at the $5 \mathrm{~cm}$ depth by

6 Hydra Probe.

7 Among the measured soil profile moisture data from four different depths $(5 \mathrm{~cm}, 20 \mathrm{~cm}, 40 \mathrm{~cm}$

8 and $60 \mathrm{~cm}$ ), data for the top $5 \mathrm{~cm}$ depth was used for assimilation. This arrangement mimics the

9 process of assimilating remotely sensed soil moisture information which is also available only

10 for the top few centimeters of the soil profile. In assimilating data at the daily time step by using

11 measurements collected at ten minute time intervals, the data collected at 11:50 PM is used to update and reinitialize the model simulation at the end of the each day.

In the EnKF application, it is important to have a good knowledge of model and observation errors to define the error covariance ( $w_{k}$ in Equation (3) and $v_{k}$ in Equation (4)). In studies that

15 use synthetic data, these errors are pre-defined, but in experiments involving actual measurements, these errors are difficult to estimate. In this study, observation errors are mainly

17 from instrument error and error from using point measured soil moisture and ignoring field-

18 variability of soil water characteristics. Model errors result from the uncertainties in model physics, soil characteristics, and forcing variables (precipitation and other meteorological data). Because these errors were difficult to estimate in this study, appropriate standard deviation of observation and model errors which minimize errors were determined by trial and error. Standard

22 deviations of model errors of 9.58E-3 and 7.20E-3 $\mathrm{m}^{3} \mathrm{~m}^{-3}$ were used for AS1 and AS2,

23 respectively, and an equal standard deviation of observation errors of $7.07 \mathrm{E}-3 \mathrm{~m}^{3} \mathrm{~m}^{-3}$ was used

24 for both sites.

25 Forecasted soil moisture at each of the four measurement depths was compared with the measured data for evaluation before the updating step. This evaluation was conducted by using

27 time series graphs and standard statistical measures. The correlation coefficient (R) was used to

28 indicate the strength of linear association between the measured and predicted soil moisture 
1 values. In addition, mean bias error (MBE; Equation (10)) and root mean square error (RMSE;

2 Equation (11)) were used to represent the prediction bias and error, respectively.

$3 \quad R M S E=\sqrt{\frac{\sum(P-O)^{2}}{n}}$

$4 \quad M B E=\frac{\sum(P-O)}{n}$

5 Where $P$ and $O$ are predicted and observed soil moisture, respectively, and $n$ is the number of 6 measurements.

\section{4. Results and Discussion}

\section{$8 \quad 4.1$ Assimilation results}

9 All modeling results presented in this study are for non calibrated conditions using a combination of measured, default and model estimated soil parameters or properties. We chose to perform non calibrated simulations to better determine the fundamental affects of data assimilation on the

12 physically-based model performance of soil moisture dynamics in the $0-60 \mathrm{~cm}$ root zone. Non calibrated RZWQM simulations were conducted at field sites AS1 and AS2 under the following

14 three conditions: (i) simulation without data assimilation (open loop); (ii) simulation with

15 direction insertion data assimilation method (DIR); and (iii) simulation with EnKF data assimilation (EnKF). As mentioned in section 3.3, the soil moisture at $5 \mathrm{~cm}$ was used for assimilation, with model predictions compared to measured data at 5, 20, 40 and $60 \mathrm{~cm}$ depths.

18 Simulation of RZWQM was conducted from April 1 (Julian day 91) to October 31 (Julian day 304) 2007 to include the effect of plant water uptake and to avoid periods of frozen soil water. Results at AS1 (beginning Julian day 125) and AS2 (beginning Julian day 115) are presented in

21 Fig. 4 and Table 2. For the EnKF simulation, 100 ensemble members were created and the

22 results shown in Fig. 4 and Table 2 are the average of ten 10 simulations.

23 Application of the EnKF improved the open loop results more than the DIR, especially by 24 increasing correlation coefficients to more than 0.90 in the top soil layer $(5 \mathrm{~cm})$ for both AS1 and 
AS2, and reducing prediction errors by 38 and $59 \%$ for AS1 and AS2, respectively, compared to

2 open loop (Table 2). The AS2 simulation had relatively poor results from the open loop, and data assimilation using both direct insertion and EnKF produced better results (increased correlation coefficients and reduced errors) for the all layers. However, results from the AS1 simulation were more complicated and will be discussed in greater detail below. The open loop simulation did not capture the dynamic variation of soil moisture conditions in the top soil layer especially during the dry-down period. In most cases, the open loop simulation overestimated soil moisture in the top layer while surface soil moisture data assimilation improved simulated soil moisture dynamics and soil moisture estimates.

The consistent discrepancies between model forecasting and observations shown in Fig. 4 can be found in other previous studies (Walker et al., 2001a; Reichle and Koster, 2004; Reichle et al., 2004). Walker et al. (2001a) concluded that removal of the systematic bias in the model forecasts or observation is essential for correct retrieval of profile soil moisture using the Kalman filter assimilation scheme. In regard to remotely sensed soil moisture data, cumulative distribution function $(\mathrm{CDF})$ matching has been used to reduce the systematic differences between satellitebased and model-based soil moisture estimates effectively (Reichle and Koster, 2004; Drusch et $a l ., 2005)$. The need for the correction or rescaling of the discrepancies (bias), before assimilating soil moisture observations into model are confirmed in this study as well. Removal of the systematic forecast bias is expected to improve assimilation results especially during the dry-down period.

The observed soil moisture data at the AS1 site (Fig. 2) shows consistently higher values of soil moisture being measured at the $40 \mathrm{~cm}$ depth compared to those at $60 \mathrm{~cm}$, which is not typical of most profile soil moisture distributions. This is because the AS1 sensor site has a dense till soil layer derived from unsorted glacial material at approximately $40 \mathrm{~cm}$ which makes the lateral flow more dominant than the vertical flow. As a result, the measured soil moisture at the $40 \mathrm{~cm}$ depth at AS1 is always higher than the soil moisture at $60 \mathrm{~cm}$ depth. Based on soil sampling data,

28 Thus, the model is unable to capture the unique phenomenon at AS1 (predicting higher water 
depth (high negative MBE in the Table 2). The EnKF reduces the open loop overestimated soil moisture at 5 and $20 \mathrm{~cm}$ and is closer to the measured values, but this change affects the soil moisture profile at 40 and $60 \mathrm{~cm}$. As a result, the initially underestimated soil moisture at $40 \mathrm{~cm}$ and $60 \mathrm{~cm}$ was further reduced to give a lower correlation coefficient and higher error (Table 2). This local phenomenon, due to the highly heterogeneous soil characteristics, is ignored in largescale data assimilation studies. However, this finding for the small field scale study points to issues that should be considered for future soil moisture data assimilation studies.

As expected from the previous studies (Walker et al., 2001b; Zhang et al., 2006), the EnKF is shown to be superior to the DIR except for the results of deeper layers at AS1. Walker et al. (2001b) illustrated the difference between the DIR and the EnKF graphically and provides a concise description of both techniques. They describe two limitations of the DIR. First, with the DIR, surface information from observations can be transferred into the deeper layers only through physical infiltration and exfiltration processes while the Kalman Filter modifies the entire soil profile using the covariances of both the surface measurements and model profile prediction. Second, DIR changes the soil moisture profile according to the difference between the measured and simulated soil moisture. The DIR results in this study revealed that the updated (reinitialized) simulated soil moisture, using the surface observations at the end of day, returns to soil moisture values very near those of the open loop after several sub-hourly simulation loops. However, the results of the EnKF are closer to measured values than the DIR (Fig. 4) resulting in better statistical results. The above-mentioned characteristics of the DIR approach had less of an effect than the EnKF at the 40 and $60 \mathrm{~cm}$ depths at AS1 (Table 2).

This study demonstrates the potential for reliable application of the EnKF for surface soil moisture assimilation. However, in spite of satisfactory model performance in this study with application of the EnKF, some precautions should be considered. One of the main reasons for the uncertainty with the EnKF appear to be the presence of bias in the model forecast and violation of the basic assumption of the EnKF (zero mean noise) because of nonlinear processes imbedded in the model and the bounded nature of soil moisture (porosity and residual water content of soil). To overcome these limitations of the EnKF with the real observations, it is desirable to adopt an appropriate bias-correction algorithm for the EnKF (De Lannoy et al., 2007a; De 
1 Lannoy et al., 2007b; Ryu et al., 2009). Second, randomly generated ensemble numbers may

2 interfere with the numerical algorithm to solve the Richards' equation in the RZWQM and lead

3 to an infinite routine. Therefore, cautious assignment of variances for the EnKF and proper

4 restriction of random numbers are necessary.

5 There appears to be inconsistencies between the field-measured soil moisture and laboratory

6 measured soil hydraulic properties as observed in Fig. 4. For both sites, field-measured soil

7 moisture at the $5 \mathrm{~cm}$ depth during the dry period (less than 0.1 ) were lower than the laboratory-

8 measured or model estimated water content at $-1500 \mathrm{kPa}$, considered the wilting point in Table 2 .

9 The field measured soil moisture content is indicative of high evaporative demand during dry-

10 down period. The RZWQM, however, does not allow the simulated soil moisture to fall below

11 the wilting point when using laboratory measured values as input. Even though the model-

12 estimated inputs for wilting point were used, the simulated soil moisture during the dry period

13 did not go below 0.146 for AS1, and 0.153 for AS2 (Table 1). This implies that calibration and

14 optimization of these values should be conducted for future model runs taking into consideration

15 that laboratory measured hydraulic properties are determined based on point-scale soil cores that

16 do not always characterize actual field conditions.

\section{$17 \quad 4.2$ Effect of update interval}

18 The effect of update interval was investigated for DIR and EnKF by varying the update interval from 1 to 14 days. AS1 simulation in Fig. 5 showed that for the $5 \mathrm{~cm}$ and $20 \mathrm{~cm}$ depths, less frequent update interval longer than four days, did not produce significant benefit from the

21 assimilation scheme even though assimilated simulation results are slightly better than ones of

22 the open loop ( 0.816 and 0.785 , $\mathrm{R}$ values for $5 \mathrm{~cm}$ and $20 \mathrm{~cm}$, respectively). Interestingly, deep

23 layers (40 and $60 \mathrm{~cm}$ depths) have worse results with the frequent update (daily and every two

24 day updates). This seems to be because of the large forecasting errors as Walker et al. (2001a)

25 showed that the accuracy of the forecasting model is more important than the temporal resolution

26 of observed data.

27 On the effect of update interval with AS2 data, even less frequent update interval improved model predictions compared to open loop simulations (Fig. 6). For instance, an update interval of 
two weeks for the $5 \mathrm{~cm}$ depth raised the correlation coefficient to 0.754 with DIR and 0.784 with EnKF compared to 0.690 with the open loop. In addition, the effect of update interval is more obvious with AS2 simulations. As the update interval increases, errors increased and correlation coefficient decreased apparently except that the results of $60 \mathrm{~cm}$ depth does not vary much with different update interval. This is due, in part, to relatively small changes in soil water content at this depth.

Two previous studies (Walker et al., 2001b; Zhang et al., 2006) investigated the effect of update interval on soil moisture profile retrieval in a desktop study using a one dimensional soil moisture equation and synthetic data. In the work of Walker et al. (2001b), full retrieval of profile soil moisture profile $(1 \mathrm{~m})$ was achieved approximately after 12 days with the DIR and 12 hours with the EnKF for the observation depth of $4 \mathrm{~cm}$ when the system was updated once every hour. Their conclusion, in regards to observation interval, was that the frequent observations are more important than observation depth using the EnKF. Zhang et al. (2006) also showed similar results for the update interval impact with a required time for full retrieval being 16 hours with the EnKF and 12 days for the DIR when updated once every hour. With a more realistic "daily" update interval, they found that the full profile retrieval took 15 days with the EnKF while the DIR failed to retrieve the full profile. The studies mentioned above were based on synthetic experimental data, whereas our current study explores the effect of update interval using actual soil moisture measurements and different governing equations in the RZWQM to find the optimal and effective update interval.

Contrary to the previous synthetic studies (Walker et al. 2001; Zhang et al. 2006), data assimilation in this study was due to the number and types of physically-based processes utilized in the RZWQM. In general, we found that more frequent updates contribute to improved model predictions and that the EnKF was superior to the DIR method of data assimilation.

\subsection{Effect of ensemble size}

As mentioned in the section 3.2, the EnKF is based on the concept of Monte Carlo methods and calculates error statistics from an ensemble of system states at the time of update. Therefore, it requires a sufficient size of ensemble numbers to obtain satisfactory estimates. However for 
1 practical and realistic applications of the EnKF, it is useful to know an appropriate size of 2 ensemble.

3 In this study, different numbers of ensemble from 50 to 500 were applied to determine how the

4 assimilation results were affected by ensemble size. With a relatively smaller ensemble size of

5 50, compared to the default value of 100, model performance improved with data assimilation

6 compared to the open loop results; the correlation coefficient increased by $12 \%$ and $13 \%$ and

7 RMSE was reduced by $38 \%$ and $13 \%$ for $5 \mathrm{~cm}$ and $20 \mathrm{~cm}$ depth, respectively for AS1 (Fig. 7).

8 For the AS2 simulation which initially had relatively poor prediction from the open loop

9 simulation, an even smaller ensemble sizes (e.g., 50) produced better results. The improvement

10 with the EnKF at AS2 with 50 ensemble numbers is more apparent than with the DIR and open

11 loop; RMSE were reduced by 59\% from the open loop results and 24\% from the DIR results for

12 the $5 \mathrm{~cm}$ depth (not shown).

13 The sensitivity of EnKF to ensemble size can be seen in Fig. 7. For AS1 data, the EnKF showed

14 little difference in the efficiency due to ensemble size for upper layers. In the case of deeper

15 layers, smaller ensemble size (50) produced poorer results compared to larger ensemble sizes.

16 Simulations using AS2 data did not show significant differences in predictions between different

17 ensemble sizes (not shown).

18 Earlier studies for surface soil moisture assimilation with the EnKF (Reichle et al., 2002a;

19 Reichle et al., 2002b) show that the EnKF estimates converge to the true states with different

20 numbers of ensemble based on synthetic experimental results using a land surface model.

21 Reichle et al. (2002b) presented that an ensemble size greater than ten outperforms the extended

22 Kalman Filter. The work of Reichle et al. (2002a) showed that larger ensemble size improved

23 results even though only 30 numbers of ensemble reduced actual errors by $55 \%$ compared to the

24 open-loop simulation. In addition, they concluded that for robust estimation of error covariance,

25 at least 500 ensemble numbers were required. Recently, Zhang, Li et al. (2006) suggested that 40

26 ensemble members were enough to represent the error covariance for their one dimensional

27 model.

\section{5. Conclusion}


1 In this study, field measured surface soil moisture was assimilated into a one dimensional

2 physically based model, RZWQM, using two different data assimilation techniques, the direct

3 insertion method and the Ensemble Kalman Filter. A key difference of this study from previous

4 studies is the use of real observational data instead of synthetic data for the EnKF assimilation

5 into a field scale water quality model. In addition, this study provides a more practical and

6 operational application of surface soil moisture assimilation using the EnKF by investigating the

7 effect of update intervals and ensemble size. This is a significant aspect in terms of the eventual

8 use of satellite soil moisture products and frequency of observations.

9 Overall, the results of this study indicate that daily assimilation of surface soil moisture resulted in more accurate soil moisture estimation in the upper more dynamic layers $(5$ and $20 \mathrm{~cm})$.

11 However, improvement of soil moisture prediction in deeper layers $(40$ and $60 \mathrm{~cm})$ is less

12 certain. Since the observed data are clustered on the top soil layers, there are limitations for the

13 corrected information from the observed surface soil moisture to propagate to the deep layers.

14 Nevertheless, unsuccessful predictions from the open loop for AS1 and AS2 were greatly

15 improved for all layers with both the DIR and the EnKF, except for deeper layers in AS1.

Unique characteristics of soil profile properties and soil moisture distribution at AS1 caused inconsistent assimilation results for the deep layers. That is, the data assimilation techniques,

18 especially the EnKF gave somewhat inadequate results at the $40 \mathrm{~cm}$ and $60 \mathrm{~cm}$ depths. Therefore, for more successful application of the EnKF, it is recommended to adjust or calibrate the model parameters before data assimilation so that the model prediction can simulate the unique field characteristics properly.

22 Even though soil hydraulic properties measured in the laboratory and estimated by the RZWQM

23 model were used for the simulation, the open loop results of AS2 highly overestimated the 24 measured soil moisture, thus failing to capture dynamic variations in the soil profile. Considering 25 uncertainties in the laboratory analysis and the high spatial variability of field soil characteristics, 26 it is recommended that the model parameters be optimized through calibration. In this study, 27 however, the model was not calibrated because the purpose of this experiment was to investigate 28 the fundamental effect of different data assimilation techniques on model output compared to the 
open loop simulation. However, it is also found a need for a proper rescaling step to remove

2 systematic errors between model forecasts and observed data which exist even after calibration.

3 The investigation into the effect of update interval in the range of 1 to 14 days found that shorter

4 update intervals improve open loop simulation results better than the long update intervals. This

5 linear relationship between the update interval and performance of the data assimilation was

6 more apparent in the upper layers with the AS2 simulation. Results of AS1 do not show

7 significant benefit from the frequent update because of its unique soil water distribution in the

8 deep layers.

9 Theoretically, the EnKF requires sufficiently large ensemble numbers to obtain satisfactory results. In this study, however, the test of the effect of the ensemble size showed that larger

11 ensemble sizes did not produce any significant improvement in the results, and an ensemble of

12100 members produced results that were comparable to results from larger ensembles.

13 Especially, the top layer at $5 \mathrm{~cm}$ depth did not show any sensitivity to the different ensemble

14 numbers. For the other deep layers, smaller ensemble size of 50 deteriorated the statistical results

15 slightly but still produced better results than the open loop and the DIR for AS2.

16 Although data assimilation was shown to contribute to better estimation of profile soil moisture,

17 there are certain additional points to consider in future studies. First, data assimilation breaks up

18 the water balance of the system. Contrary to the above-mentioned synthetic experiments, the 19 RZWQM includes very sophisticated physical processes; varying boundary conditions due to

20 surface interaction with atmosphere and fluctuating water table depth, and plant water uptake and

21 tile drainage as sink terms. Artificial interruption from the surface soil moisture assimilation

22 affects all these processes and further work is necessary to determine to what extent data

23 assimilation impacts them. Therefore, future investigations involving data assimilation will

24 include the assessment of other hydrologic variables such as ET, runoff, as well as water quality 25 parameters and crop yield. 


\section{References}

Abrahamson DA, Radcliffe DE, Steiner JL, Cabrera ML, Endale DM, Hoogenboom G. 2006. Evaluation of the RZWQM for simulating tile drainage and leached nitrate in the Georgia piedmont. Agronomy Journal 98(3): 644-654.

Abrahamson DA, Radcliffe DE, Steiner JL, Cabrera ML, Hanson JD, Rojas KW, Schomberg HH, Fisher DS, Schwartz L, Hoogenboom G. 2005. Calibration of the root zone water quality model for simulating tile drainage and leached nitrate in the Georgia Piedmont. Agronomy Journal 97(6): 1584-1602.

Ahuja L, Rojas KW, Hanson JD, Shaffer MJ, Ma L. 2000. Root Zone Water Quality Model: Modeling Management Effects on Water Quality and Crop Production, Water Resources Publications LLC, Highlands Ranch, CO.

Baup F, Mougin E, Rosnay Pd, Timouk F, Chênerie I. 2007. Surface soil moisture estimation over the AMMA Sahelian site in Mali using ENVISAT/ASAR data. Remote Sensing of Environment 109: 473-481.

Burgers G, van Leeuwen PJ, Evensen G. 1998. Analysis scheme in the Ensemble Kalman Filter. Monthly Weather Review 126: 1719.

Cameira MR, Ahuja L, Fernando RM, Pereira LS. 2000. Evaluating field measured soil hydraulic properties in water transport simulations using the RZWQM. Journal of Hydrology 236(1-2): 7890.

Cameira MR, Fernando RM, Ahuja L, Pereira L. 2005. Simulating the fate of water in field soil-crop environment. Journal of Hydrology 315(1-4): 1-24.

Chen F, Crow WT, Starks PJ, Moriasi DN. 2011. Improving hydrologic predictions of a catchment model via assimilation of surface soil moisture. Advances in Water Resources 34(4): 526-536.

Crosson WL, Laymon CA, Inguva R, Schamschula MP. 2002. Assimilating remote sensing data in a surface flux-soil moisture model. Hydrological Processes 16(8): 1645-1662.

Crow WT, Wood EF. 2003. The assimilation of remotely sensed soil brightness temperature imagery into a land surface model using Ensemble Kalman filtering: a case study based on ESTAR measurements during SGP97. Advances in Water Resources 26(2): 137-149.

De Lannoy GJM, Houser PR, Pauwels VRN, Verhoest NEC. 2007a. State and bias estimation for soil moisture profiles by an ensemble Kalman filter: Effect of assimilation depth and frequency. Water Resources Research 43.

De Lannoy GJM, Houser PR, Verhoest NEC, Pauwels VRN. 2009. Adaptive soil moisture profile filtering for horizontal information propagation in the independent column-based CLM2.0. Journal of Hydrometeorology 10(3): 766-779.

De Lannoy GJM, Reichle RH, Houser PR, Pauwels VRN, Verhoest NEC. 2007b. Correcting for forecast bias in soil moisture assimilation with the ensemble Kalman filter. Water Resources Research 43.

Draper CS, Mahfouf JF, Walker JP. 2009. An EKF assimilation of AMSR-E soil moisture into the ISBA land surface scheme. Journal of Geophysical Research - Atmospheres 114.

Drusch M, Wood EF, Gao H. 2005. Observation operators for the direct assimilation of TRMM microwave imager retrieved soil moisture. Geophysical Research Letters 32.

Evensen G. 1994. Sequential data assimilation with a nonlinear quasi-geostrophic model using Monte Carlo methods to forecast error statistics. Journal of Geophysical Research - Oceans 99: 1014310162.

Evensen G. 2003. The Ensemble Kalman Filter: theoretical formulation and practical implementation. Ocean Dynamics 53: 343-367.

Evensen G. 2004. Sampling strategies and square root analysis schemes for the EnKF. Ocean Dynamics 54: 539-560. 
Evensen G, Leeuwen PJv. 1996. Assimilation of Geosat altimeter data for the Agulhas current using the ensemble Kalman filter with a quasigeostrophic model. Monthly Weather Review 124(1): 85.

Farahani HJ, Buchleiter GW, Ahuja LR, Peterson GA, Sherrod LA. 1999. Seasonal evaluation of the root zone water quality model in Colorado. Agronomy Journal 91(2): 212-219.

Gelb A. (1974). "Applied optimal estimation." The MIT Press, 374.

Heathman GC, Starks PJ, Ahuja LR, Jackson TJ. 2003a. Assimilation of surface soil moisture to estimate profile soil water content. Journal of Hydrology 279: 1-17.

Heathman GC, Starks PJ, Brown MA. 2003b. Time domain reflectometry field calibration in the Little Washita River Experimental Watershed. Soil Science Society of America Journal 67(1): 52-61.

Hoeben R, Troch PA. 2000. Assimilation of active microwave observation data for soil moisture profile estimation. Water Resources Research 36.

Houser PR, Shuttleworth WJ, Famiglietti JS, Gupta HV, Syed KH, Goodrich DC. 1998. Integration of soil moisture remote sensing and hydrologic modeling using data assimilation. Water Resources Research 34(12): 3405-3420.

Houtekamer PL, Mitchell HL. 1998. Data assimilation using an Ensemble Kalman Filter technique. Monthly Weather Review 126: 796.

Houtekamer PL, Mitchell HL. 2001. A sequential ensemble Kalman Filter for atmospheric data assimilation. Monthly Weather Review 129(1): 123.

Huang C, Li X, Lu L, Gu J. 2008. Experiments of one-dimensional soil moisture assimilation system based on ensemble Kalman filter. Remote Sensing of Environment 112: 888-900.

Jackson TJ, Gasiewski AJ, Oldak A, Klein M, Njoku EG, Yevgrafov A, Christiani S, Bindlish R. 2002. Soil Moisture Retrieval Using the C-Band Polarimetric Scanning Radiometer during the Southern Great Plains 1999 Experiment. IEEE Transactions on Geoscience and Remote Sensing 40(10): 2151-2161.

Jackson TJ, Schmugge TJ. 1989. Passive microwave remote sensing system for soil moisture: some supporting research. IEEE Transactions on Geoscience and Remote Sensing 27(2): 225-235.

Jackson TJ, Vine DEL. 1996. Mapping surface soil moisture using a aircraft-based passive microwave instrument: algorithm and example. Journal of Hydrology 184: 85-99.

Jackson TJ, Vine DML, Swifi CT, Schmugge TJ, Schiebe FR. 1995. Large area mapping of soil moisture using the ESTAR passive microwave radiometer in Washita'92. Remote Sensing of Environment 53: $27-37$.

Keppenne CL. 2000. Data assimilation into a primitive-equation model with a parallel Ensemble Kalman Filter. Monthly Weather Review 128: 1971.

Kozak JA, Ahuja LR, Green TR, Ma LW. 2007. Modelling crop canopy and residue rainfall interception effects on soil hydrological components for semi-arid agriculture. Hydrological Processes 21(2): 229-241.

Li J, Islam S. 1999. On the estimation of soil moisture profile and surface fluxes partitioning from sequential assimilation of surface layer soil moisture. Journal of Hydrology 220(1-2): 86-103.

Ma L, Ahuja LR, Ascough JC, Shaffer MJ, Rojas KW, Malone RW, Cameira MR. 2001. "Integrating system modeling with field research in agriculture: Applications of the root zone water quality model (RZWQM)." Advances in Agronomy, Vol 71, 233-292.

Ma L, Ahuja LR, Malone RW. 2007a. Systems modeling for soil and water research and management: Current status and needs for the 21st century. Transactions of the ASABE 50(5): 1705-1713.

Ma L, Malone RW, Heilman P, Ahuja LR, Meade T, Saseendran SA, Ascough JC. 2007b. Sensitivity of tile drainage flow and crop yield on measured and calibrated soil hydraulic properties. Geoderma 140(3): 284-296.

Ma L, Malone RW, Heilman P, Karlen DL, Kanwar RS, Cambardella CA, Saseendran SA, Ahuja LR. 2007c. RZWQM simulation of long-term crop production, water and nitrogen balances in Northeast Iowa. Geoderma 140(3): 247-259. 
Ma L, Nielsen DC, Ahuja LR, Malone RW, Saseendran SA, Rojas KW, Hanson JD, Benjamin JG. 2003. Evaluation of RZWQM under varying irrigation levels in eastern Colorado. Transactions of the ASAE 46(1): 39-49.

Margulis SA, McLaughlin D, Entekhabi D, Dunne S. 2002. Land data assimilation and estimation of soil moisture using measurements from the Southern Great Plains 1997 Field Experiment. Water Resources Research. 38.

Mattikalli NM, Engman ET, Ahuja LR, Jackson TJ. 1998. Microwave remote sensing of soil moisture for estimation of profile soil property. International Journal of Remote Sensing 19(9): 1751-1767.

Ni-Meister W. 2008. Recent Advances On Soil Moisture Data Assimilation. Physical Geography 29(1): 19-37.

Ni-Meister W, Houser PR, Walker JP. 2006. Soil moisture initialization for climate prediction: Assimilation of scanning multifrequency microwave radiometer soil moisture data into a land surface model. Journal of Geophysical Research-Atmospheres 111(D20): 15.

Njoku EG, Jackson TJ, Lakshmi V, Chan TK, Nghiem SV. 2003. Soil moisture retrieval from AMSR-E. IEEE Transactions on Geoscience and Remote Sensing 41(2): 215-229.

Rawls WJ, Brakensiek DL, Saxton KE. 1982. Estimation of soil-water properties. Transactions of the ASAE 25(5): 1316-1320.

Reichle RH, Koster RD. 2004. Bias reduction in short records of satellite soil moisture. Geophysical Research Letters 31.

Reichle RH, Koster RD. 2005. Global assimilation of satellite surface soil moisture retrievals into the NASA Catchment land surface model. Geophysical Research Letters 32(2): 4.

Reichle RH, Koster RD, Dong JR, Berg AA. 2004. Global soil moisture from satellite observations, land surface models, and ground data: Implications for data assimilation. Journal of Hydrometeorology 5(3): 430-442.

Reichle RH, Koster RD, Liu P, Mahanama SPP, Njoku EG, Owe M. 2007. Comparison and assimilation of global soil moisture retrievals from the Advanced Microwave Scanning Radiometer for the Earth Observing System (AMSR-E) and the Scanning Multichannel Microwave Radiometer (SMMR). Journal of Geophysical Research - Atmospheres 112.

Reichle RH, McLaughlin DB, Entekhabi D. 2002a. Hydrologic data assimilation with the Ensemble Kalman Filter. Monthly Weather Review 130: 103-114.

Reichle RH, Walker JP, Koster RD, Houser PR. 2002b. Extended versus Ensemble Kalman Filtering for land data assimilation. Journal of Hydrometeorology 3: 728-740.

Ryu D, Crow WT, Zhan X, Jackson TJ. 2009. Correcting unintended perturbation biases in hydrologic data assimilation. Journal of Hydrometeorology 10(3): 734-750.

Schmugge T, Jackson TJ. 1994. Mapping surface soil moisture with microwave radiometers. Meteorology and Atmospheric Physics 54: 213-223.

Seuffert G, Wilker H, Viterbo P, Drusch M, Mahfouf JF. 2004. The usage of screen-level parameters and microwave brightness temperature for soil moisture analysis. Journal of Hydrometeorology 5(3): 516-531.

Seyfried MS, Grant LE, Du E, Humes K. 2005. Dielectric loss and calibration of the Hydra Probe soil water sensor. Vadose Zone Journal 4(4): 1070-1079.

Seyfried MS, Murdock MD. 2004. Measurement of soil water content with a 50-MHz soil dielectric sensor. Soil Science Society of America Journal 68(2): 394-403.

Starks PJ, Heathman GC, Ahuja LR, Ma L. 2003. Use of limited soil property data and modeling to estimate root zone soil water content. Journal of Hydrology 272(1-4): 131-147.

Topp GC, Davis JL. 1985. Measurement of soil water content using time-domain reflectrometry (TDR): A field evaluation. Soil Science Society of America Journal 49(1): 19-24.

Topp GC, Davis JL, Annan AP. 1980. Electromagnetic determination of soil water content: Measurements in coaxial transmission lines. Water Resources Research 16(3): 574-582. 
Troch PA, Paniconi C, McLaughlin D. 2003. Catchment-scale hydrologic modeling and data assimilation. Advances in Water Resources 26: 131-135.

Verstraeten WW, Veroustraete F, van der Sande CJ, Grootaers I, Feyen J. 2006. Soil moisture retrieval using thermal inertia, determined with visible and thermal spaceborne data, validated for European forests. Remote Sensing of Environment 101(3): 299-314.

Walker JP, Houser PR. 2001. A methodology for initializing soil moisture in a global climate model: Assimilation of near-surface soil moisture observations. Journal of Geophysical ResearchAtmospheres 106(D11): 11761-11774.

Walker JP, Willgoose GR, Kalma JD. 2001a. One-dimensional soil moisture profile retrieval by assimilation of near-surface measurements: A simplified soil moisture model and field application. Journal of Hydrometeorology 2(4): 356-373.

Walker JP, Willgoose GR, Kalma JD. 2001b. One-dimensional soil moisture profile retrieval by assimilation of near-surface observations: a comparison of retrieval algorithms. Advances in Water Resources 24: 631-650.

Walker JP, Willgoose GR, Kalma JD. 2002. Three-dimensional soil moisture profile retrieval by assimilation of near-surface measurements: Simplified Kalman filter covariance forecasting and field application. Water Resources Research 38(12).

Whitaker JS, Hamill TM. 2002. Ensemble data assimilation without perturbed observations. Monthly Weather Review 130(7): 1913-1924.

Xie XH, Zhang DX. 2010. Data assimilation for distributed hydrological catchment modeling via ensemble Kalman filter. Advances in Water Resources 33(6): 678-690.

Zhang S, Li H, Zhang W, Qiu C, Li X. 2006. Estimating the soil moisture profile by assimilating nearsurface observations with the ensemble Kalman filter (EnKF). Advances in Atmospheric Sciences 22(6): 936-945. 


\section{List of Figures.}

Figure 1. Study Area- AS1 and AS2 sites.

Figure 2. Observed rainfall and soil water content at 5, 20, 40 and $60 \mathrm{~cm}$ depth

(Observation period: May 5 to October 31 for AS1 and April 25 to October 31 for AS2 in 2007).

Figure 3. Framework of RZWQM and EnKF Scheme.

Figure 4. Comparison of observed and assimilated soil moisture at $5(\mathrm{a}, \mathrm{b})$ and $20 \mathrm{~cm}$.

Figure 5. Effects of update intervals with DIR ( $a$ and $b$ ) and $\operatorname{EnKF}(c$ and $d$ ) for AS1.

Figure 6. Effects of update intervals with DIR ( $a$ and $b$ ) and EnKF ( $c$ and $d$ ) for AS2.

Figure 7. Effects of ensemble size on the correlation coefficient and RMSE for AS1.

\section{List of Tables.}

Table 1. Soil physical and hydraulic properties.

Table 2. Statistical data analysis (simulation period: April October, 2007). 


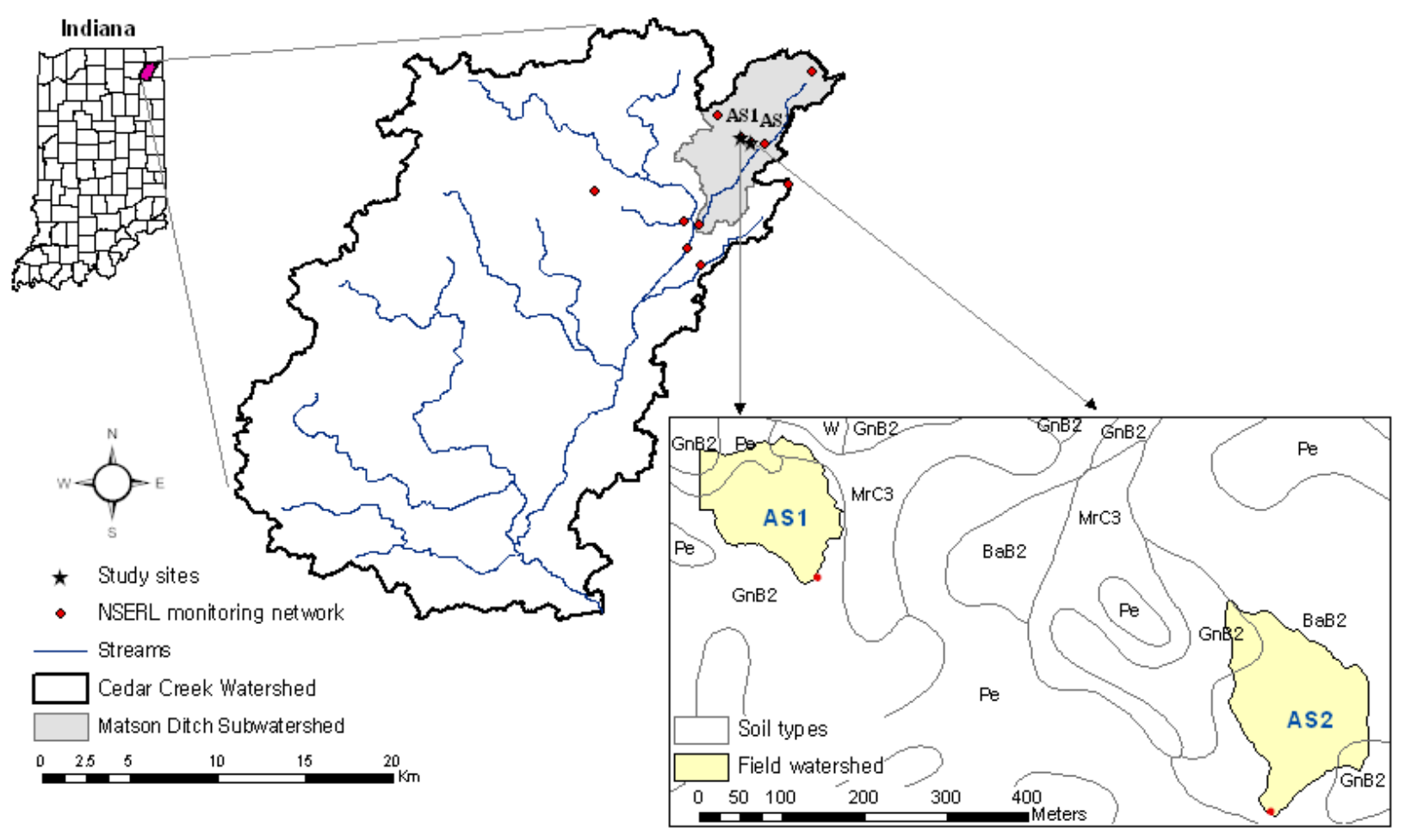

Figure 1. Study area in Upper Cedar Creek Watershed and AS1 and AS2 field sites. 


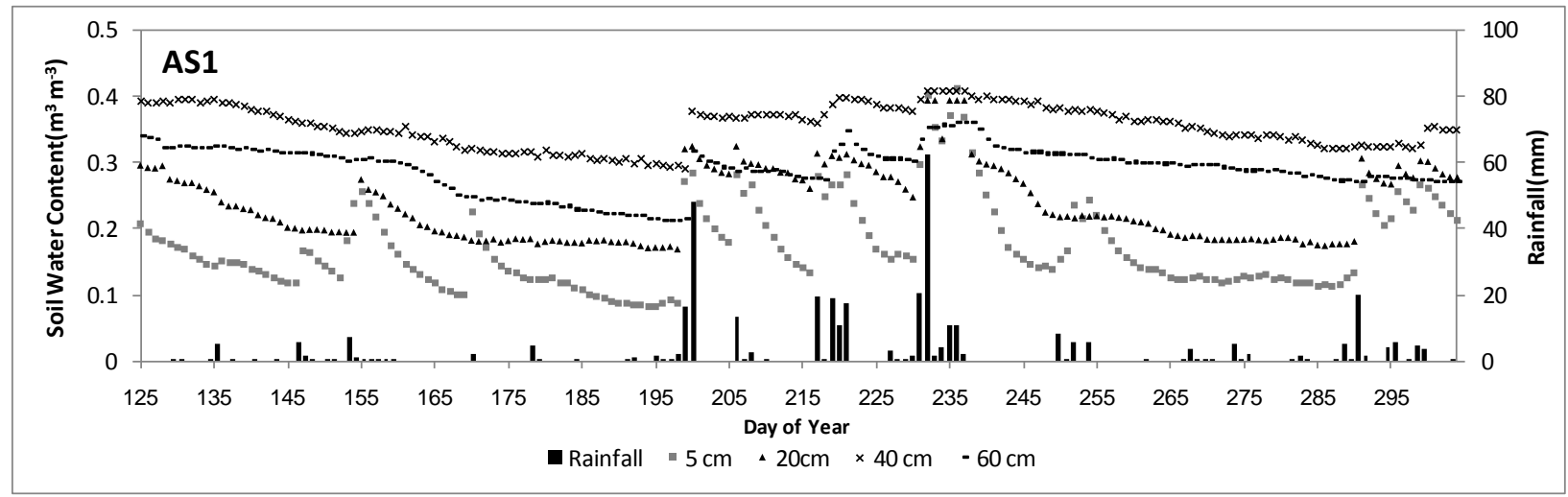

(a)

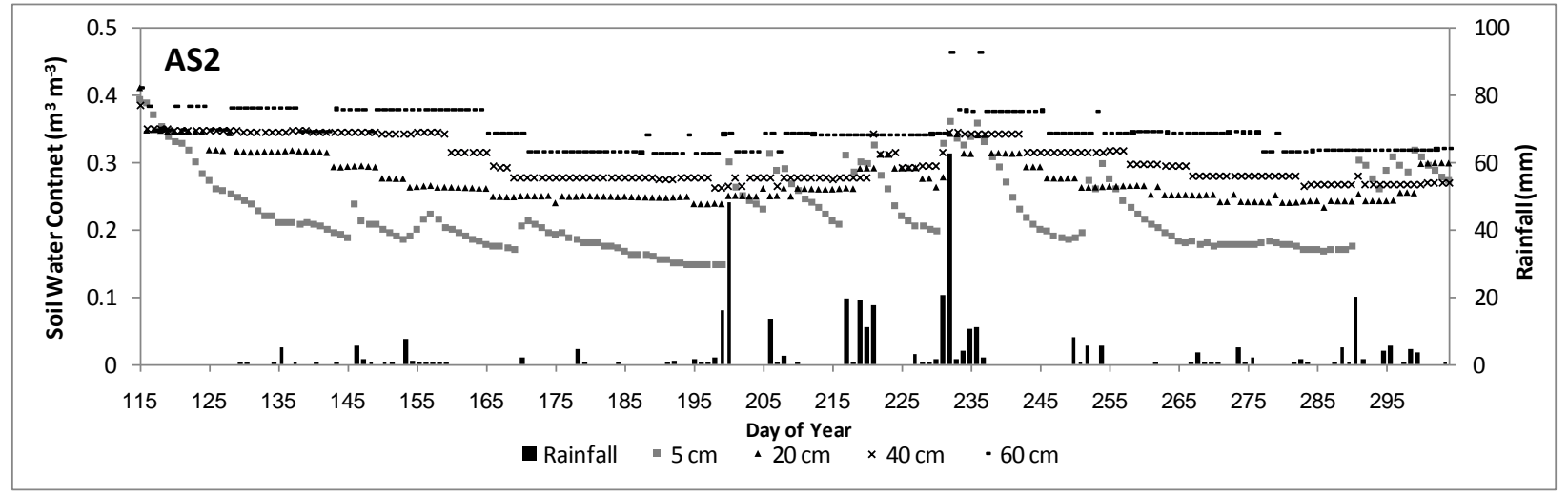

(b)

Figure 2. Observed rainfall and soil water content at 5, 20, 40 and $60 \mathrm{~cm}$ depth at (a) field AS1 and (b) field AS2. (Observation period: May 5 to October 31 for AS1 and April 25 to October 31 for AS2 in 2007). 


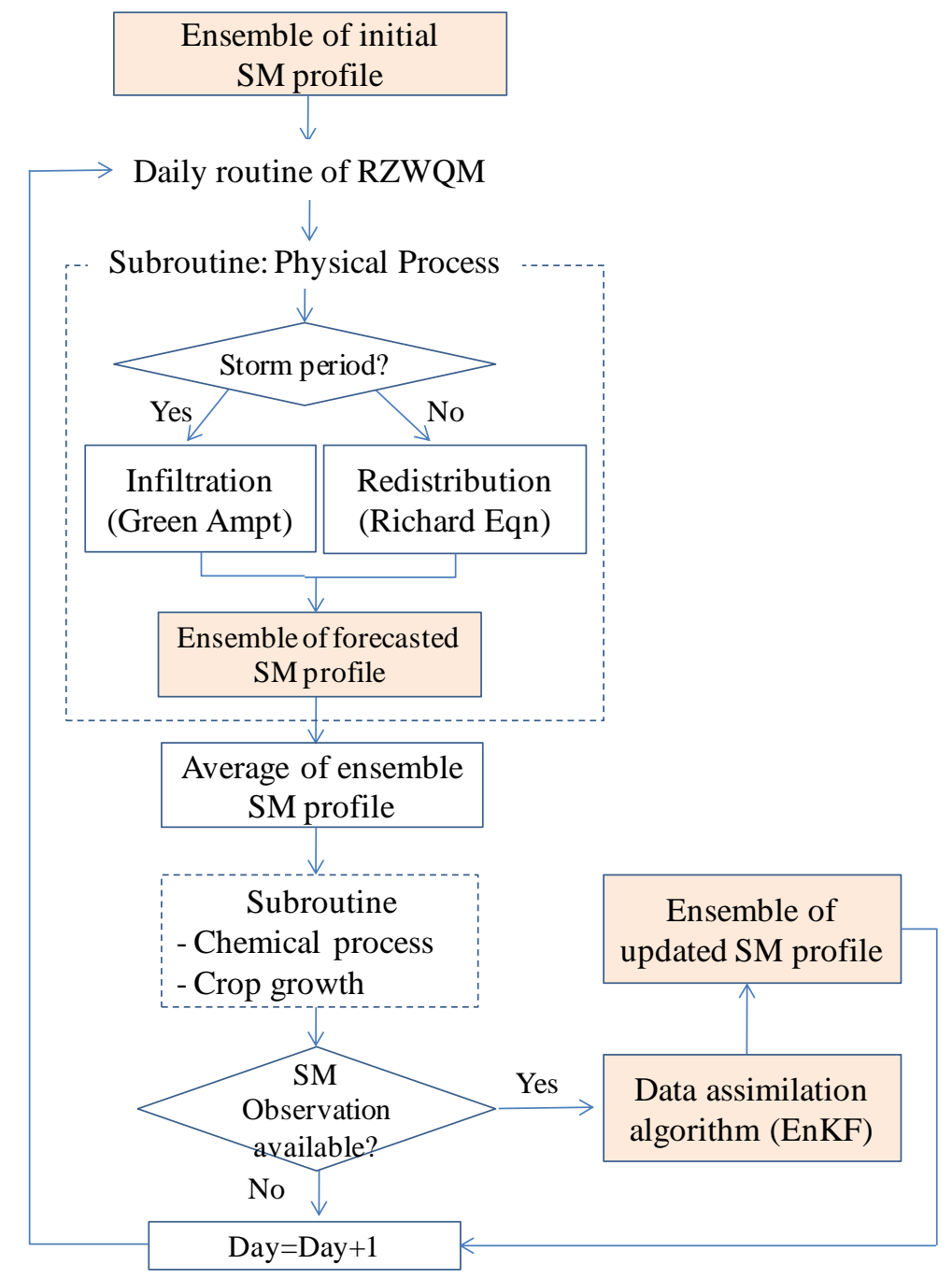

Figure 3. Framework of RZWQM and EnKF Scheme. 


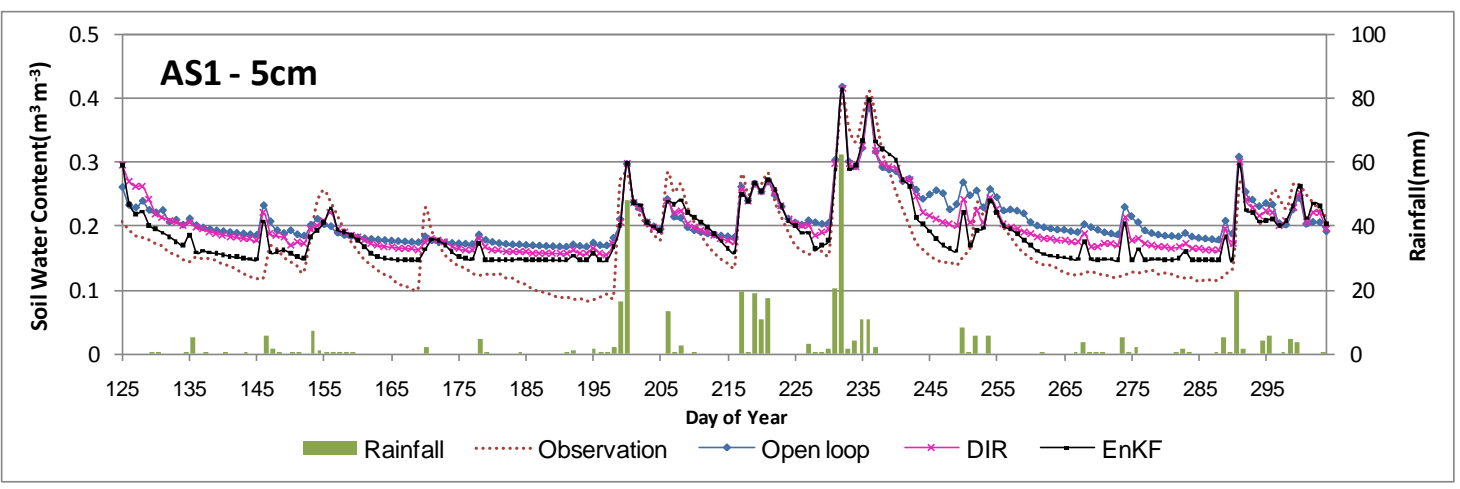

(a)

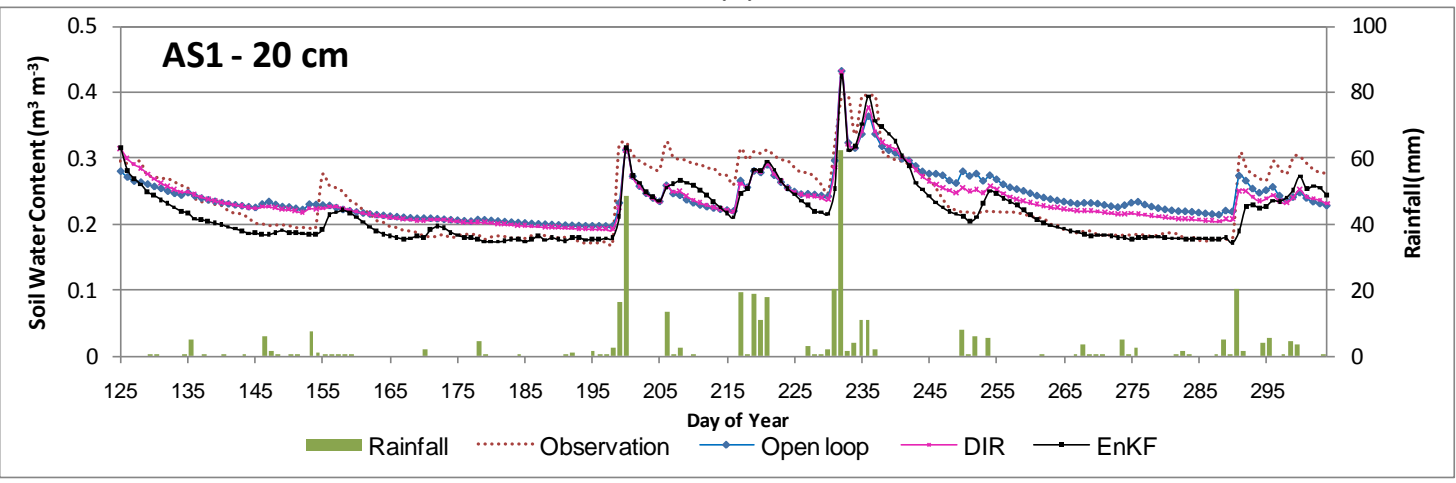

(b)

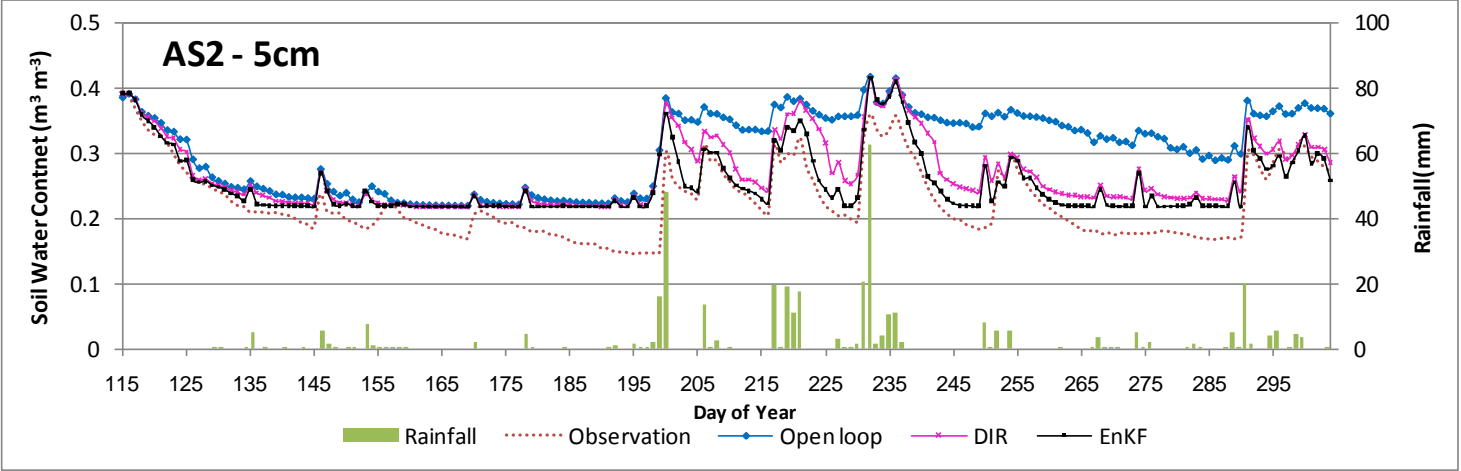

(c)

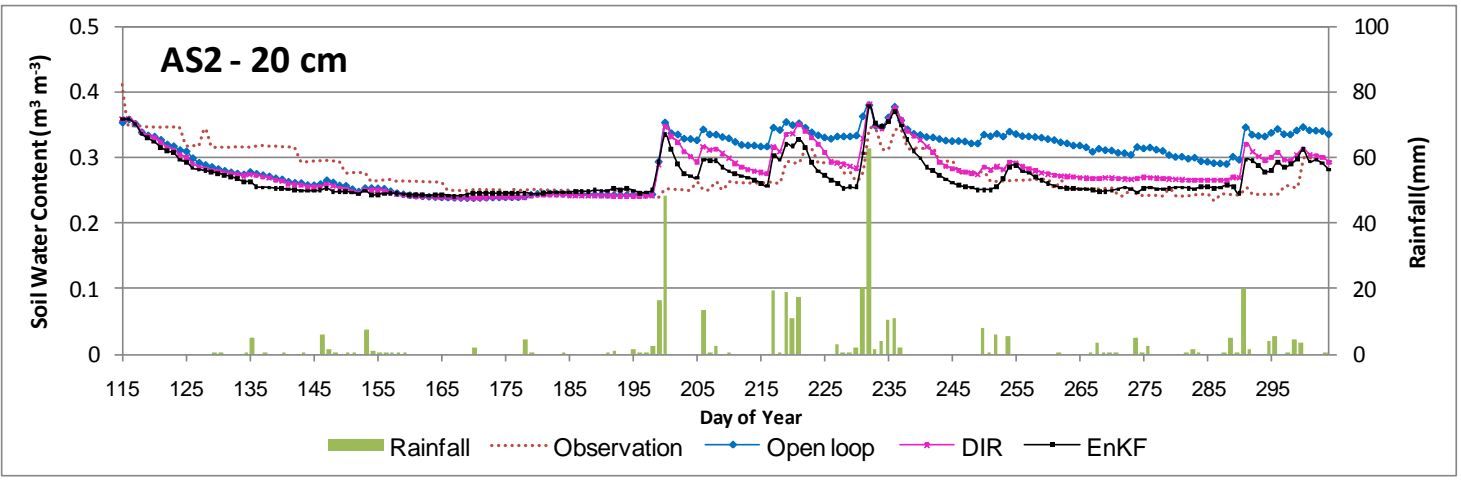

(d)

Figure 4. Comparison of observed and assimilated soil moisture at 5 (a and c) and $20 \mathrm{~cm}$ (b and d). 
(a) Correlation coefficient

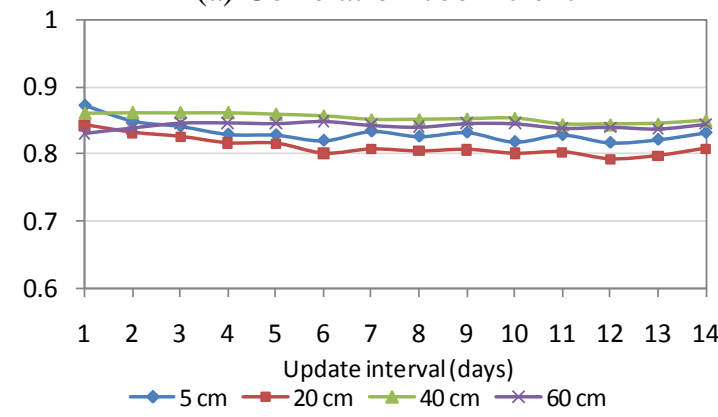

(c) Correlation coefficient

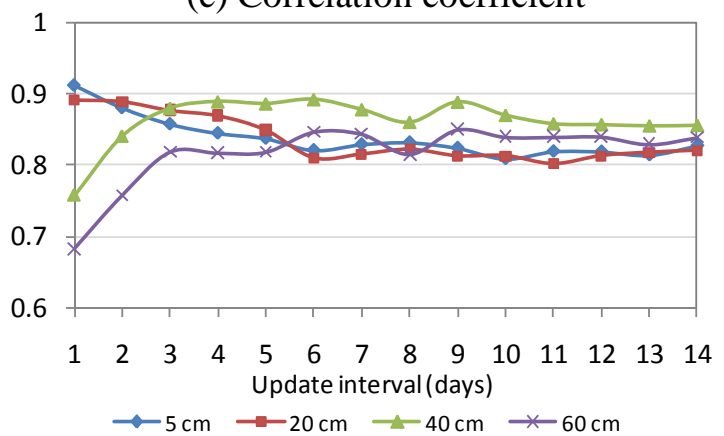

(b) RMSE

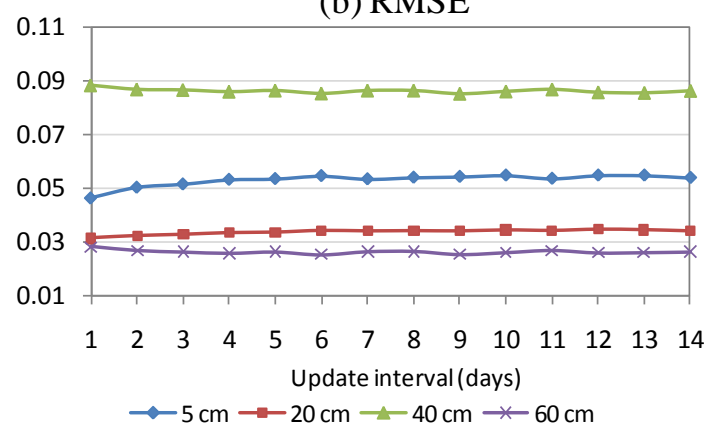

(d) RMSE

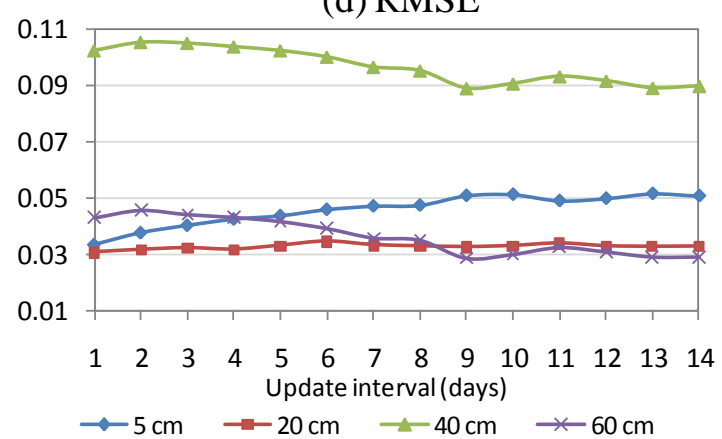

Figure 5. Effects of update intervals with DIR (a and b) and EnKF (c and d) for AS1. 
(a) Correlation coefficient

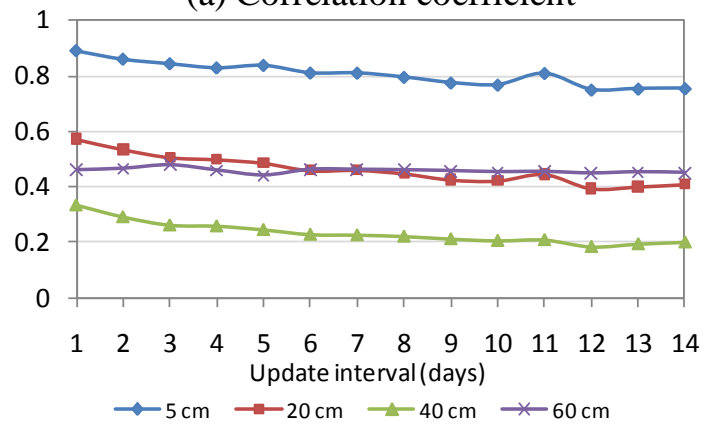

(c) Correlation coefficient

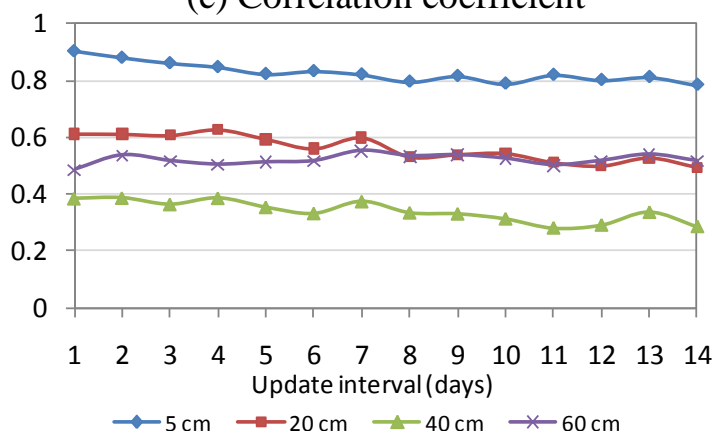

(b) RMSE

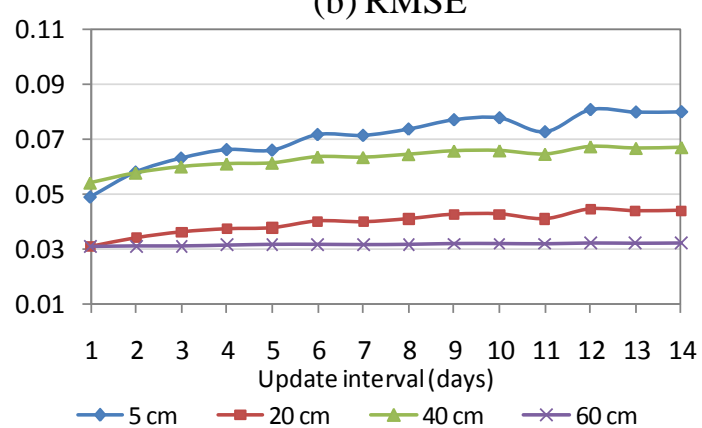

(d) RMSE

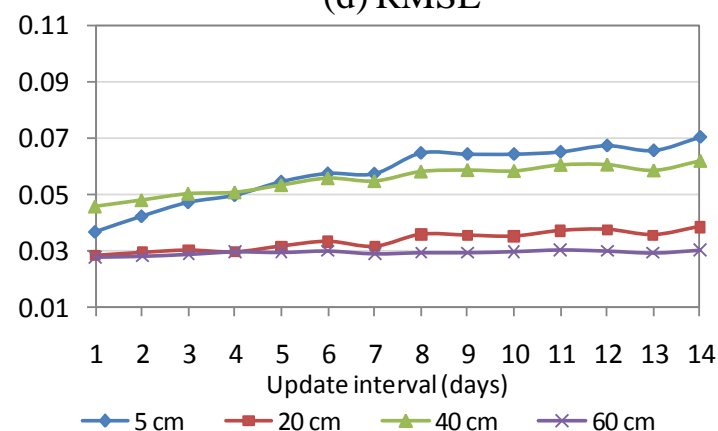

Figure 6. Effects of update intervals with DIR (a and b) and EnKF (c and d) for AS2. 

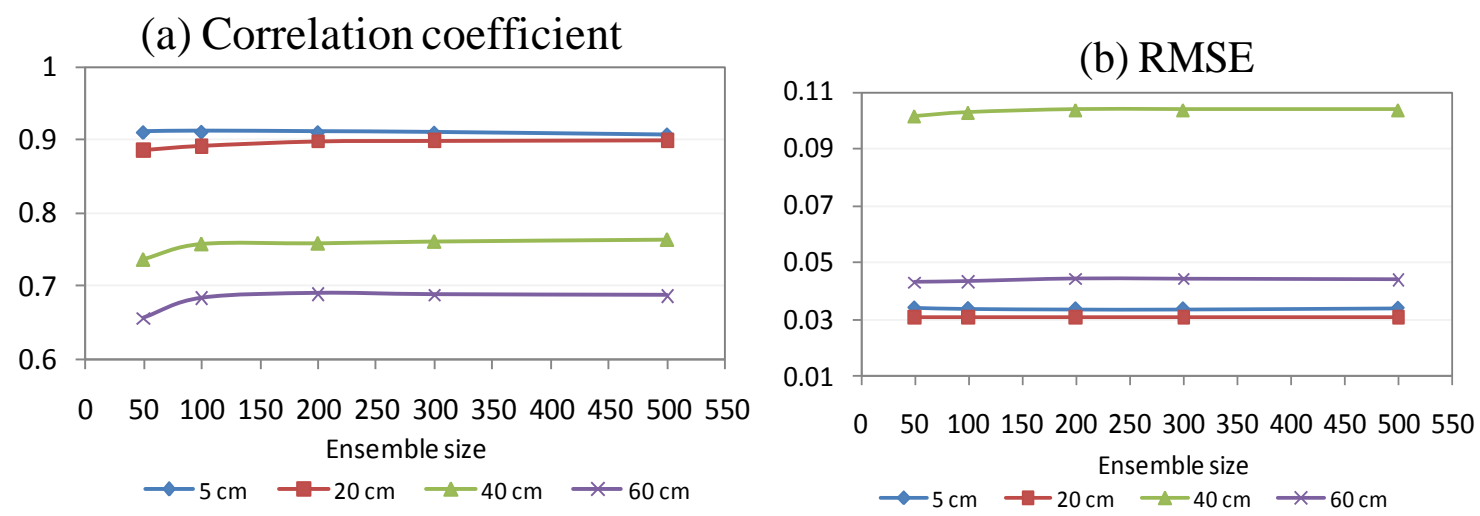

Figure 7. Effects of ensemble size on the (a) correlation coefficient and (b) RMSE for AS1. 
Table 1. Soil physical and hydraulic properties

\begin{tabular}{|c|c|c|c|c|c|c|c|c|c|c|}
\hline \multirow[b]{2}{*}{ Site } & \multirow[b]{2}{*}{$\begin{array}{l}\text { Depth } \\
(\mathrm{cm})\end{array}$} & \multicolumn{7}{|c|}{ Measured in laboratory } & \multicolumn{2}{|c|}{ Model estimation } \\
\hline & & $\begin{array}{c}\text { Soil }^{\text {a) }} \\
\text { Texture } \\
\end{array}$ & $\begin{array}{c}\text { Sand } \\
(\%) \\
\end{array}$ & $\begin{array}{l}\text { Silt } \\
(\%) \\
\end{array}$ & $\begin{array}{l}\text { Clay } \\
(\%) \\
\end{array}$ & $\begin{array}{c}\text { Bulk density } \\
\left(\mathrm{g} \mathrm{cm}^{3}\right) \\
\end{array}$ & $\begin{array}{c}\mathrm{FC}^{\mathrm{b})} \\
\left(\mathrm{m}^{3} \mathrm{~m}-{ }^{3}\right)\end{array}$ & $\begin{array}{c}\text { WP }{ }^{\mathrm{c})} \\
\left(\mathrm{m}^{3} \mathrm{~m}-{ }^{3}\right) \\
\end{array}$ & $\begin{array}{c}\mathrm{WP}^{\mathrm{c})} \\
\left(\mathrm{m}^{3} \mathrm{~m}-{ }^{3}\right) \\
\end{array}$ & $\begin{array}{c}\mathrm{Ks}^{\mathrm{d})} \\
\left(\mathrm{cm} \mathrm{h}^{-1}\right) \\
\end{array}$ \\
\hline \multirow{5}{*}{ AS1 } & $0-5$ & $\mathrm{~L}$ & 51.3 & 31.6 & 17.1 & \multirow{2}{*}{1.42} & \multirow{2}{*}{0.303} & \multirow{2}{*}{0.207} & \multirow{2}{*}{0.146} & \multirow{2}{*}{1.91} \\
\hline & $5-15$ & $\mathrm{~L}$ & 42.3 & 37.0 & 20.7 & & & & & \\
\hline & $15-30$ & $\mathrm{~L}$ & 37.6 & 36.3 & 26.0 & 1.49 & 0.318 & 0.246 & 0.153 & 1.32 \\
\hline & $30-45$ & SCL & 45.7 & 23.4 & 30.9 & 1.44 & 0.349 & 0.282 & 0.176 & 0.49 \\
\hline & $45-60$ & CL & 36.4 & 27.1 & 36.5 & 1.48 & 0.351 & 0.293 & 0.207 & 0.30 \\
\hline \multirow{5}{*}{ AS2 } & $0-5$ & $\mathrm{~L}$ & 30.8 & 45.4 & 23.8 & \multirow{2}{*}{1.39} & \multirow{2}{*}{0.318} & \multirow{2}{*}{0.218} & \multirow{2}{*}{0.153} & \multirow{2}{*}{1.76} \\
\hline & $5-15$ & $\mathrm{~L}$ & 27.7 & 46.0 & 26.4 & & & & & \\
\hline & $15-30$ & CL & 25.4 & 33.4 & 41.3 & 1.53 & 0.305 & 0.236 & 0.185 & 0.66 \\
\hline & $30-45$ & CL & 26.3 & 38.0 & 35.7 & 1.40 & 0.358 & 0.293 & 0.210 & 0.60 \\
\hline & $45-60$ & $\mathrm{CL}$ & 25.1 & 39.4 & 35.5 & 1.38 & 0.346 & 0.298 & 0.205 & 1.00 \\
\hline
\end{tabular}

a) Acronym for soil texture: $\mathrm{SCL}=$ sandy clay loam, $\mathrm{CL}=$ clay loam, $\mathrm{L}=$ loam, $\mathrm{C}=$ clay

b) FC: field capacity, water content at $-33 \mathrm{kPa}$

c) WP: wilting point, water content at $-1500 \mathrm{kPa}$

d) Ks: Saturated hydraulic conductivity 
Table 2. Statistical data analysis (simulation period: April October, 2007)

\begin{tabular}{|c|c|c|c|c|c|c|c|c|c|c|}
\hline \multirow{2}{*}{ Site } & \multirow{2}{*}{$\begin{array}{c}\text { Depth } \\
(\mathrm{cm})\end{array}$} & \multicolumn{3}{|c|}{ Open Loop } & \multicolumn{3}{|c|}{ Direct Insertion } & \multicolumn{3}{|c|}{ EnKF } \\
\hline & & $\mathrm{R}$ & RMSE & MBE & $\mathrm{R}$ & RMSE & MBE & $\mathrm{R}$ & RMSE & MBE \\
\hline \multirow{4}{*}{$\begin{array}{l}\text { A } \\
S \\
1\end{array}$} & 5 & 0.816 & 0.055 & 0.038 & 0.873 & 0.046 & 0.030 & 0.912 & 0.034 & 0.018 \\
\hline & 20 & 0.785 & 0.035 & 0.003 & 0.843 & 0.031 & -0.001 & 0.892 & 0.031 & -0.018 \\
\hline & 40 & 0.836 & 0.086 & -0.084 & 0.861 & 0.088 & -0.087 & 0.757 & 0.103 & -0.099 \\
\hline & 60 & 0.834 & 0.027 & -0.018 & 0.831 & 0.028 & -0.020 & 0.683 & 0.043 & -0.031 \\
\hline \multirow{4}{*}{$\begin{array}{l}\text { A } \\
S \\
2\end{array}$} & 5 & 0.690 & 0.091 & 0.078 & 0.891 & 0.049 & 0.042 & 0.904 & 0.037 & 0.028 \\
\hline & 20 & 0.320 & 0.050 & 0.024 & 0.573 & 0.031 & 0.005 & 0.612 & 0.029 & -0.005 \\
\hline & 40 & 0.109 & 0.073 & 0.056 & 0.336 & 0.054 & 0.041 & 0.383 & 0.046 & 0.034 \\
\hline & 60 & 0.412 & 0.033 & 0.022 & 0.460 & 0.031 & 0.019 & 0.485 & 0.028 & 0.015 \\
\hline
\end{tabular}

